\title{
A Brief Review on Advantages of Nano-based Drug Delivery Systems
}

\author{
Zahra Hami ${ }^{1, *}$ \\ ${ }^{1}$ Toxicology Research Center, AJA University of Medical Sciences, Tehran, Iran \\ "Corresponding author: Toxicology Research Center, AJA University of Medical Sciences, Tehran, Iran. Email: hamiz1357@yahoo.com \\ Received 2020 December 19; Revised 2021 January 13; Accepted 2021 January 24.
}

\begin{abstract}
Context: During the past two decades, the development of drug delivery systems based on nanomaterials has yielded nanocarriers for smart application in nanomedicine to treat diseases.

Evidence Acquisition: The current review presents a summary of some advances in the development and application of nanodelivery systems for improving the efficacy of conventional drugs and reducing their adverse effects through the production of smart delivery carriers with targeting moieties and controlled release strategies used in therapy. The searches were conducted in ScienceDirect, Scopus, Google Scholar, and PubMed databases for relevant studies.

Results: As reviewed in the present paper, the investigated targeted drug delivery systems have proven to be more effective than free drugs by enhancing efficacy and reducing the systemic toxicity of therapy. In addition, many studies have shown remarkable advantages of nanoscale drug delivery carriers regarding the possibility to improve properties such as solubility, stability, absorption, diffusivity, bioavailability, targeting, and controlled release of drugs.

Conclusions: Despite many advantages of nanoscale drug delivery systems reported in the medical literature, deeper research about the composition, synthesis, characteristics, and clinical applications in this area is needed.
\end{abstract}

Keywords: Nanomedicine, Nanomaterials, Drug Delivery, Drug Targeting

\section{Context}

Efficient drug delivery with nanocarriers for effective and safe therapy has been developed during the last decades. Nanomaterial-based drug delivery systems (DDS) can deliver drugs to the target diseased cells in a controlled release manner. Nanomaterials (NMs) and nanoparticles (NPs) can be defined as the material with structures on the nanoscale dimension (between 1 and $100 \mathrm{~nm}$ ) (1). As known, NMs and NPs exhibit tunable and unique physicochemical, mechanical, electrical, and biological characteristics. These special properties are due to the decreased size and increased surface area of them. As a result of the large surface area to volume ratio, NMs show quantum effects and special properties (2). Currently, nanomedicine has received attention by utilizing NMs and nanostructures as DDS (3). Drug delivery systems can deliver drugs to target tissues in a controlled release manner. Drugs can be chemically conjugated or physically encapsulated in these nanocarriers (4-6). The small size and high surface area of nanomaterials allow them to enter cells and interact with biomolecules easily. Improving absorption, bioavailability, and stability can be achieved by using nanotechnology in drug delivery, and therefore overcome the defects of common DDS.

Nanostructured delivery carriers can protect encapsulated drugs from in vivo degradation. On the other hand, the first-pass effect can be prevented by using DDS, especially in the case of water-insoluble drugs (7). The most widely used nano-based drug delivery carriers are micelles $(8,9)$, liposomes $(10,11)$, carbon nanotubes $(12)$, solid lipid nanoparticles (SLN) $(13,14)$, dendrimers (15), mesoporous silica NPs (16), gold NPs (17, 18), quantum dots (QD) (19), and superparamagnetic iron-oxide nanoparticles (SPIONs) $(20,21)$. Polymeric nanomicelles are widely used as drug delivery systems. Some notable advantages of these carriers are biocompatibility, biodegradability, ease of preparation, and good loading and delivery efficacy (22-24). Amphiphilic polymers can be easily self-assembled into nanomicelles. Diblock copolymers composed of hydrophilic and hydrophobic blocks with variable lengths can encapsulate hydrophobic drugs in the core of the nanomicelle and/or attach hydrophilic drugs on the surface in the aqueous medium (25). Some common polymers used in the composition of nanomicelles are poly(ethylene glycol) (PEG) (26), N-(2-hydroxypropyl) methacrylamide (HPMA) (27), poly(l-lactic acid) (PLA) (28), poly(lactic-co-glycolic acid) (PLGA) (29), polycaprolactone (PCL) (30), and chi- 
tosan $(31,32)$. Most polymeric nanomicelles investigated for drug delivery applications have been used successfully in cancer. Examples of these nanomicelles are Genexol PM (33), NK911 (34), NK105 (35), NK012 (36), and NC6004 (37).

Many anticancer drugs are hydrophobic compounds, and nanomicelles with amphiphilic copolymers can solubilize them without using harmful organic solvents. On the other hand, targeting ligands on the surface of micelles target a specific receptor on cancerous cells and increase anticancer efficacy of the drug by accumulation in the site of action, on top of cell uptake enhancement. Nanoliposomes (also known as lipid-based nanovesicles) are versatile DDS made of bilayer lipids with an aqueous reservoir. This composition allows the delivery of hydrophilic and hydrophobic drugs. Nanoliposomes are good candidates for various applications in nanomedicine and nanobiotechnology because of their safety, stability, biocompatibility, and biodegradability. In comparison with polymeric nanomicelles, nanoliposomes have an improved drug release profile. Some nanoliposome formulations in drug delivery studies are DOXIL/Caelyx (38), Myocet (39), Depocyt (40), Daunoxome (41), CPX-1 (42), and CPX-571 (43).

One of the most important aspects of nanoscale DDS is the ability of targeting, which makes a smart DDS that only affects the diseased tissue. Nanoscale targeted drug delivery systems increase the concentration of the drug in the site of action, improve its efficacy, and reduce adverse side effects of the encapsulated drug. These advantages have led to targeted nanoscale DDS being highly regarded in research and therapeutics (44-46). The knowledge about diseases at the molecular level will help us in better targeting DDS development. Some modifications on the surface of DDS can cause a better accumulation of DDS near the diseased cells and improved uptake into the cells. These modifiers or ligands have widely been used in drug delivery investigations as targeting agents. This strategy is known as active targeting. In this approach, the imposed ligands on the surface of DDS bind with high affinity to specific components on the surface of diseased cells. Some targeting moieties investigated include antibodies, folate, lectins, peptides, aptamers, transferrin, lactobionic acid, oligosaccharides, and albumin (47).

Nanostructured DDS can also provide controlled drug release by applying some modifications in the composition. Uncontrolled drug release may lead to the release of the encapsulated drug in the wrong site and consequently reduce the appropriate amount of the drug in the target tissue and increase its adverse side effects. In the case of nanoliposomal carriers, hydrogel embedded inside the liposome could successfully control the release of the drug. Another approach is the $\mathrm{pH}$-sensitive release with polymeric nanomicelles in cancer therapy. These nanocarriers release the drug specifically in an acidic $\mathrm{pH}$ of the tumor environment. Polymers with ionizable functional groups are unstable in response to $\mathrm{pH}$ variations and thus release the encapsulated or conjugated drugs by structure destruction. Another manner is an acid-labile linker that can be used between copolymers and the drug to achieve controlled release in tumoral acidic $\mathrm{pH}$. These two $\mathrm{pH}$ sensitive release manners are shown in Figure 1. Some acid-labile bonds investigated in controlled release studies are hydrazone, oxime, imine, orthoester, and vinyl ether bonds. These two approaches have been extensively studied $(48,49)$, and the results have shown that in the latter approach, the drug release was lower than in the former approach because the polymeric structure of DDS was not destructed. Advances in nanoscale DDS are presented in this review.

\section{Evidence Acquisition}

The current review presents a summary of some advances in the development and application of nanodelivery systems for improving the efficacy of conventional drugs and reducing their adverse effects through the production of smart delivery carriers with targeting moieties and controlled release strategies used in therapy. The literature searches were conducted in ScienceDirect, Scopus, Google Scholar, and PubMed databases for relevant research articles up to 2020. The following keywords were used to identify the relevant articles: Drug delivery systems, nanocarriers, nanomaterials, nanomedicine, targeting delivery, and controlled release.

\section{Results}

The results listed in Table 1 were extracted from selected original reports.

\section{Conclusions}

The current review highlights advances in drug delivery through NM-based drug delivery systems. The common types of advanced nanocarriers include liposome formulations, polymeric carriers, micellar formulations, nanocrystals, protein nanoparticles, and many others for efficient transport and release of drugs at the disease site. A growing number of research studies in this area showed that nano-delivery carriers play an important role in the improvement of some types of therapy and can effectively overcome the problems of solubility, bioavailability, stability, targeting, and controlled release, as well 
Drug

Hydrophilic Polymer

Hydrophobic Polymer with Ionizable Functional Groups

Drug

Hydrophilic Polymer

Hydrophobic Polymer

Acid-labile Bond
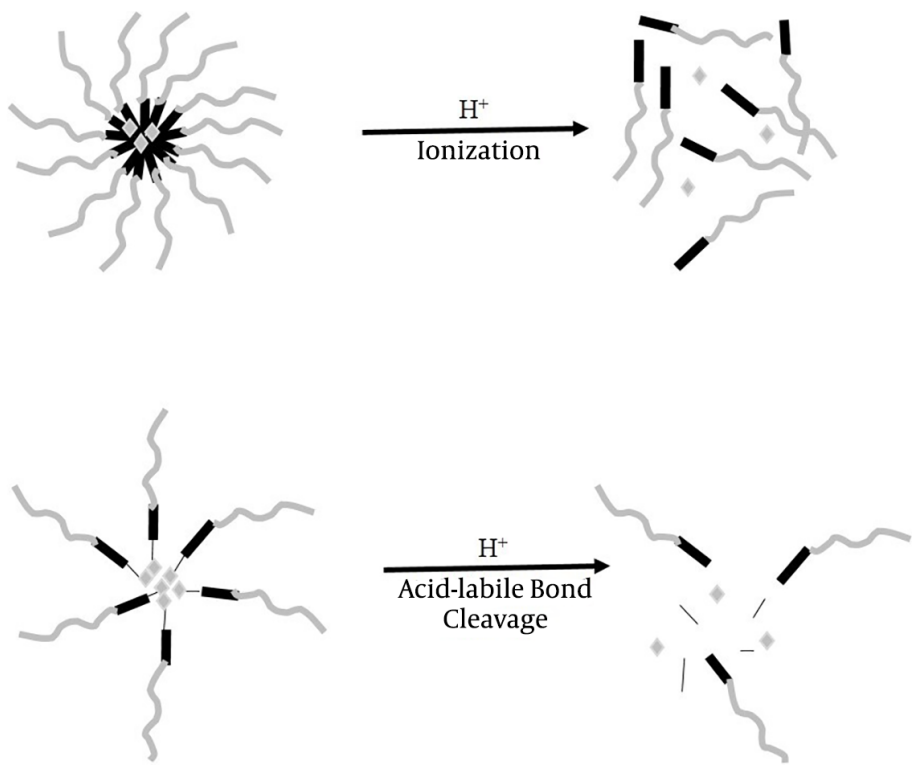

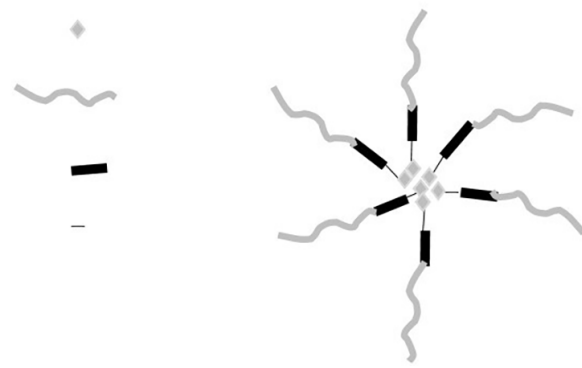

Figure 1. A schematic representation of two pH-sensitive release mechanisms of polymeric nanomicelles; 1 , pH-induced structure ionization and destruction leads to drug release; 2 , The cleavage of the acid-labile linkage between the polymer and drug leads to drug release.

\begin{tabular}{|c|c|c|}
\hline Nanocarrier + Drug & Indication (s) & Outcomes \\
\hline Liposomal daunorubicin (DaunoXome $®)(50)$ & Kaposi's sarcoma & $\begin{array}{l}\text { Enhanced delivery to the tumor site; Decreased side } \\
\text { effects and systemic toxicity. }\end{array}$ \\
\hline $\begin{array}{l}\text { Liposomal amphotericin B lipid complex (Abelcet } 囚 \text { ) } \\
\text { (51) }\end{array}$ & Fungal infections & Decreased toxicity \\
\hline Micellar estradiol (Estrasorb $\left.{ }^{\mathrm{TM}}\right)(52)$ & Menopausal therapy & $\begin{array}{l}\text { Improved efficacy by controlled delivery of the } \\
\text { therapeutic agent. }\end{array}$ \\
\hline Micellar DOX-Hyd-PLA-PEG-FOL (53) & Ovarian cancer & $\begin{array}{l}\text { Targeted and controlled release of the drug, improved } \\
\text { anticancer efficacy, decreased systemic toxicity. }\end{array}$ \\
\hline $\begin{array}{l}\text { Albumin-bound paclitaxel Nanoparticles } \\
\text { (Abraxane }(\text { ) }(54)\end{array}$ & Breast cancer; NSCLC; Pancreatic cancer & Enhanced solubility; Increased delivery to the tumor. \\
\hline Morphine sulfate nanocrystals (55) & Psychostimulant & Improved drug loading and bioavailability; Slow release. \\
\hline Paliperidone palmitate nanocrystals (56) & Schizophrenia; Schizoaffective disorder & Extended-release of drugs with low solubility. \\
\hline Dantrolene sodium nanocrystals (57) & Malignant hypothermia & Administration of higher doses of the drug. \\
\hline $\begin{array}{l}\text { Ferumoxytol SPION with polyglucose sorbitol } \\
\text { carboxymethylether }(58)\end{array}$ & Chronic kidney failure with iron deficiency & Decreased number of doses, extended-release \\
\hline Micellar P123-PAE/Cur (59) & Cancer therapy & $\begin{array}{l}\text { Longer circulation, } \mathrm{pH} \text {-responsive controlled release, } \\
\text { increased accumulation at the tumor site. }\end{array}$ \\
\hline Micellar DTX-LEV-Hyd-PLA-PEG-FOL/DTX (60) & Ovarian cancer & $\begin{array}{l}\text { Targeted and controlled release of the drug, improved } \\
\text { anticancer efficacy, decreased systemic toxicity. }\end{array}$ \\
\hline mPEG-TK-PLGA/ atorvastatin (61) & Acute kidney injury & $\begin{array}{l}\text { Great ability to ROS-responsive drug release, target } \\
\text { mitochondria, superior antioxidant, and anti-apoptotic } \\
\text { activity. }\end{array}$ \\
\hline C-dots/ transferrin+ epirubicin, Temozolomide (62) & Glioblastoma brain tumors & $\begin{array}{l}\text { Targeted delivery, improved anticancer efficacy, } \\
\text { synergistic effects by two-drug combination in the } \\
\text { nanocarrier. }\end{array}$ \\
\hline SLN + gelling system/MOX (63) & Psychostimulant & $\begin{array}{l}\text { Improved encapsulation efficiency, controlled release of } \\
\text { the drug, prolonged action in a sustained manner. }\end{array}$ \\
\hline
\end{tabular}


as decrease side effects of drugs. Active targeting and stimuli-responsive controlled release of drugs are very useful strategies for smart drug delivery by nanocarriers. However, the complexity of in vivo environments can influence the efficacy of nanoscale delivery carriers for treatment purposes. However, with the deep and precise study of the molecular mechanism of diseases and more advances in nanotechnology, the DDS and their applications in nanomedicine can be improved. Nanomedicine is among one of the most attractive science branches, and in recent years, a great deal of research has been done on drug delivery systems based on nanotechnology. Despite many advances in the synthesis and application of drug carriers, there are still weaknesses. More pharmaceutical studies are needed in the case of size, composition, surface functional groups, drug loading, targeting agents, and controlled release factors in future nanocarriers. Another approach is to consider the potentially hazardous effects of nanocarriers on humans and the environment. In other words, risk and benefit must be considered simultaneously. Although many studies have been done in this area, additional research is needed. The future of nanomedicine with targeted delivery and controlled release of drugs is a promising therapy.

\section{Footnotes}

Authors' Contribution: Conceptualization, searching for related articles, drafting, and revision of the manuscript, Zahra Hami.

Conflict of Interests: The author declares no conflict of interest.

Funding/Support: No funding is reported.

\section{References}

1. Sajid M. Toxicity of nanoscale metal organic frameworks: a perspective. Environ Sci Pollut Res Int. 2016;23(15):14805-7. doi: 10.1007/s11356016-7053-y. [PubMed: 27300166].

2. Cheng LC, Jiang X, Wang J, Chen C, Liu RS. Nano-bio effects: Interaction of nanomaterials with cells. Nanoscale. 2013;5(9):3547-69. doi: 10.1039/c3nr34276j. [PubMed: 23532468].

3. Singh S. Nanomedicine-nanoscale drugs and delivery systems. $J$ Nanosci Nanotechnol. 2010;10(12):7906-18. doi: 10.1166/jnn.2010.3617. [PubMed: 21121278].

4. Allen TM, Cullis PR. Drug delivery systems: Entering the mainstream. Science. 2004;303(5665):1818-22. doi: 10.1126/science.1095833. [PubMed: 15031496].

5. Wilczewska AZ, Niemirowicz K, Markiewicz KH, Car H. Nanoparticles as drug delivery systems. Pharmacol Rep. 2012;64(5):1020-37. doi: 10.1016/s1734-1140(12)70901-5.

6. Hami Z, Salarian AA. [Synthesis and loading of nanocurcumin on iron magnetic nanoparticles modified with chitosan]. Tehran Univ Med J. 2020;77(11):715-9. Persian.
7. Ghosh S, Ghosh S, Sil PC. Role of nanostructures in improvising oral medicine. Toxicol Rep. 2019;6:358-68. doi: 10.1016/j.toxrep.2019.04.004. [PubMed: 31080743]. [PubMed Central: PMC6502743].

8. Kim Y, Pourgholami MH, Morris DL, Stenzel MH. Effect of cross-linking on the performance of micelles as drug delivery carriers: A cell uptake study. Biomacromolecules. 2012;13(3):814-25. doi: 10.1021/bm201730p. [PubMed: 22276949].

9. Kwon GS, Okano T. Polymeric micelles as new drug carriers. Adv Drug Deliv Rev. 1996;21(2):107-16. doi: 10.1016/s0169-409x(96)00401-2.

10. Voinea M, Simionescu M. Designing of 'intelligent' liposomes for efficient delivery of drugs. J Cell Mol Med. 2002;6(4):465-74. doi: 10.1111/j.1582-4934.2002.tb00450.x. [PubMed: 12611636]. [PubMed Central: PMC6741336].

11. Malam Y, Loizidou M, Seifalian AM. Liposomes and nanoparticles: Nanosized vehicles for drug delivery in cancer. Trends Pharmacol Sci. 2009;30(11):592-9. doi: 10.1016/j.tips.2009.08.004. [PubMed: 19837467].

12. Zhang $\mathrm{W}$, Zhang Z, Zhang $\mathrm{Y}$. The application of carbon nanotubes in target drug delivery systems for cancer therapies. Nanoscale Res Lett. 2011;6:555. doi: 10.1186/1556-276X-6-555. [PubMed: 21995320]. [PubMed Central: PMC3210734].

13. Mukherjee S, Ray S, Thakur RS. Solid lipid nanoparticles: A modern formulation approach in drug delivery system. Indian J Pharm Sci. 2009;71(4):349-58. doi: 10.4103/0250-474X.57282. [PubMed: 20502539]. [PubMed Central: PMC2865805].

14. Shastri DH. Effective delivery routes and strategies for solid lipid nanoparticles (SIn) and nanostructured lipid carriers (Nlc). Curr Pharm Des. 2017;23(43):6592-601. doi: 10.2174/1381612823666171122111132. [PubMed: 29173154].

15. Tripathy S, K Das M. Dendrimers and their applications as novel drug delivery carriers. J Appl Pharm Sci. 2013;3(9):142-9. doi: 10.7324/japs.2013.3924.

16. Alyassin Y, Sayed EG, Mehta P, Ruparelia K, Arshad MS, Rasekh M, et al. Application of mesoporous silica nanoparticles as drug delivery carriers for chemotherapeutic agents. Drug Discov Today. 2020;25(8):151320. doi: 10.1016/j.drudis.2020.06.006. [PubMed: 32561300].

17. Kong FY, Zhang JW, Li RF, Wang ZX, Wang WJ, Wang W. Unique roles of gold nanoparticles in drug delivery, targeting and imaging applications. Molecules. 2017;22(9). doi: 10.3390/molecules22091445. [PubMed: 28858253]. [PubMed Central: PMC6151763].

18. Bagga P, Ansari TM, Siddiqui HH, Syed A, Bahkali AH, Rahman MA, et al. Bromelain capped gold nanoparticles as the novel drug delivery carriers to aggrandize effect of the antibiotic levofloxacin. EXCLI J. 2016;15:772-80. doi: 10.17179/excli2016-710. [PubMed: 28337108]. [PubMed Central: PMC5318683].

19. Qiu J, Zhang R, Li J, Sang Y, Tang W, Rivera Gil P, et al. Fluorescent graphene quantum dots as traceable, $\mathrm{pH}$-sensitive drug delivery systems. Int J Nanomedicine. 2015;10:6709-24. doi: 10.2147/IJN.S91864. [PubMed: 26604747]. [PubMed Central: PMC4630193].

20. Miranda MS, Rodrigues MT, Domingues RMA, Costa RR, Paz E, Rodriguez-Abreu C, et al. Development of inhalable superparamagnetic iron oxide nanoparticles (SPIONs) in microparticulate system for antituberculosis drug delivery. Adv Healthc Mater. 2018;7(15). e1800124. doi: 10.1002/adhm.201800124. [PubMed: 29797461].

21. Hami Z. Coating iron oxide nanoparticles with chitosan for targeted delivery of nanocurcumin. Annals of Military and Health Sciences Research. 2020;18(1). doi: 10.5812/amh.103657.

22. Tanbour R, Martins AM, Pitt WG, Husseini GA. Drug delivery systems based on polymeric micelles and ultrasound: A review. Curr Pharm Des. 2016;22(19):2796-807. doi: 10.2174/1381612822666160217125215. [PubMed: 26898742].

23. Miyata K, Christie R, Kataoka K. Polymeric micelles for nanoscale drug delivery. React Funct Polym. 2011;71(3):227-34. doi: 10.1016/j.reactfunctpolym.2010.10.009. 
24. Hami Z, Rezayat SM, Gilani K, Amini M, Ghazi-Khansari M. In-vitro cytotoxicity and combination effects of the docetaxel-conjugated and doxorubicin-conjugated poly(lactic acid)-poly(ethylene glycol)folate-based polymeric micelles in human ovarian cancer cells. $J$ Pharm Pharmacol. 2017;69(2):151-60. doi: 10.1111/jphp.12675. [PubMed: 28044342].

25. Zhang S, Wu Y, He B, Luo K, Gu Z. Biodegradable polymeric nanoparticles based on amphiphilic principle: construction and application in drug delivery. Sci China Chem. 2014;57(4):461-75. doi: 10.1007/s11426014-5076-0.

26. Zhang K, Tang X, Zhang J, Lu W, Lin X, Zhang Y, et al. PEGPLGA copolymers: Their structure and structure-influenced drug delivery applications. J Control Release. 2014;183:77-86. doi: 10.1016/j.jconrel.2014.03.026. [PubMed: 24675377].

27. Talelli M, Rijcken CJ, van Nostrum CF, Storm G, Hennink WE. Micelles based on HPMA copolymers. Adv Drug Deliv Rev. 2010;62(2):231-9. doi: 10.1016/j.addr.2009.11.029. [PubMed: 20004693].

28. Huang S, Yu X, Yang L, Song F, Chen G, Lv Z, et al. The efficacy of nimodipine drug delivery using mPEG-PLA micelles and mPEG-PLA/TPGS mixed micelles. Eur J Pharm Sci. 2014;63:187-98. doi: 10.1016/j.ejps.2014.07.007. [PubMed: 25063034].

29. Chen X, Chen J, Li B, Yang X, Zeng R, Liu Y, et al. PLGA-PEG-PLGA triblock copolymeric micelles as oral drug delivery system: In vitro drug release and in vivo pharmacokinetics assessment. J Colloid Interface Sci. 2017;490:542-52. doi:10.1016/j.jcis.2016.11.089. [PubMed: 27923139].

30. Kheiri Manjili HR, Malvandi H, Mosavi M, Danafar H. Preparation and physicochemical characterization of biodegradable mPEG-PCL coreshell micelles for delivery of artemisinin. Pharm Sci. 2016;22(4):23443. doi: 10.15171/ps.2016.37.

31. Mahmoodzadeh F, Jannat B, Ghorbani M. Chitosan-based nanomicelle as a novel platform for targeted delivery of methotrexate. Int J Biol Macromol. 2019;126:517-24. doi: 10.1016/j.ijbiomac.2018.12.223. [PubMed: 30593812].

32. Xu X, Sun L, Zhou L, Cheng Y, Cao F. Functional chitosan oligosaccharide nanomicelles for topical ocular drug delivery of dexamethasone. Carbohydr Polym. 2020;227:115356. doi: 10.1016/j.carbpol.2019.115356. [PubMed: 31590850].

33. Lee KS, Chung HC, Im SA, Park YH, Kim CS, Kim SB, et al. Multicenter phase II trial of Genexol-PM, a Cremophor-free, polymeric micelle formulation of paclitaxel, in patients with metastatic breast cancer. Breast Cancer Res Treat. 2008;108(2):241-50. doi: 10.1007/s10549-0079591-y. [PubMed: 17476588].

34. Matsumura Y, Hamaguchi T, Ura T, Muro K, Yamada Y, Shimada Y, et al. Phase I clinical trial and pharmacokinetic evaluation of NK911, a micelle-encapsulated doxorubicin. Br J Cancer. 2004;91(10):1775-81. doi: 10.1038/sj.bjc.6602204. [PubMed: 15477860]. [PubMed Central: PMC2410050].

35. Hamaguchi T, Matsumura Y, Suzuki M, Shimizu K, Goda R, Nakamura I, et al. NK105, a paclitaxel-incorporating micellar nanoparticle formulation, can extend in vivo antitumour activity and reduce the neurotoxicity of paclitaxel. Br J Cancer. 2005;92(7):1240-6. doi: 10.1038/sj.bjc.6602479. [PubMed: 15785749]. [PubMed Central: PMC2361981].

36. Matsumura Y. Preclinical and clinical studies of NK012, an SN-38-incorporating polymeric micelles, which is designed based on EPR effect. Adv Drug Deliv Rev. 2011;63(3):184-92. doi: 10.1016/j.addr.2010.05.008. [PubMed: 20561951].

37. Plummer R, Wilson RH, Calvert H, Boddy AV, Griffin M, Sludden J, et al. A Phase I clinical study of cisplatin-incorporated polymeric micelles (NC-6004) in patients with solid tumours. BrJCancer. 2011;104(4):5938. doi: 10.1038/bjc.2011.6. [PubMed: 21285987]. [PubMed Central: PMC3049602].

38. Wibroe PP, Ahmadvand D, Oghabian MA, Yaghmur A, Moghimi SM. An integrated assessment of morphology, size, and complement activation of the PEGylated liposomal doxorubicin products Doxil@, Caelyx®, DOXOrubicin, and SinaDoxosome.JControl Release. 2016;221:1-8. doi: 10.1016/j.jconrel.2015.11.021. [PubMed: 26608877].

39. Leonard RC, Williams S, Tulpule A, Levine AM, Oliveros S. Improving the therapeutic index of anthracycline chemotherapy: Focus on liposomal doxorubicin (Myocet). Breast. 2009;18(4):218-24. doi: 10.1016/j.breast.2009.05.004. [PubMed:19656681].

40. Phuphanich S, Maria B, Braeckman R, Chamberlain M. A pharmacokinetic study of intra-CSF administered encapsulated cytarabine (DepoCyt $\AA$ ) for the treatment of neoplastic meningitis in patients with leukemia, lymphoma, or solid tumors as part of a phase III study. J Neurooncol. 2007;81(2):201-8. doi: 10.1007/s11060-006-9218-X. [PubMed: 16941075].

41. Fassas A, Anagnostopoulos A. The use of liposomal daunorubicin (DaunoXome) in acute myeloid leukemia. Leuk Lymphoma. 2005;46(6):795-802. doi: 10.1080/10428190500052438. [PubMed: 16019523 .

42. Batist G, Gelmon KA, Chi KN, Miller WJ, Chia SK, Mayer LD, et al. Safety, pharmacokinetics, and efficacy of CPX-1 liposome injection in patients with advanced solid tumors. Clin Cancer Res. 2009;15(2):692700. doi: 10.1158/1078-0432.CCR-08-0515. [PubMed: 19147776].

43. Chiu GN, Wong MY, Ling LU, Shaikh IM, Tan KB, Chaudhury A, et al. Lipid-based nanoparticulate systems for the delivery of anti-cancer drug cocktails: Implications on pharmacokinetics and drug toxicities. Curr Drug Metab. 2009;10(8):861-74. doi: 10.2174/138920009790274531. [PubMed: 20214582].

44. Bae YH, Park K. Targeted drug delivery to tumors: myths, reality and possibility. J Control Release. 2011;153(3):198-205. doi: 10.1016/j.jconrel.2011.06.001. [PubMed: 21663778]. [PubMed Central: PMC3272876].

45. Muro S. Challenges in design and characterization of ligand-targeted drug delivery systems. J Control Release. 2012;164(2):125-37. doi: 10.1016/j.jconrel.2012.05.052. [PubMed: 22709588]. [PubMed Central: PMC3481020].

46. Kwon IK, Lee SC, Han B, Park K. Analysis on the current status of targeted drug delivery to tumors. J Control Release. 2012;164(2):108-14. doi: 10.1016/j.jconrel.2012.07.010. [PubMed: 22800574]. [PubMed Central: PMC3833679].

47. Li M, Zhang W, Wang B, Gao Y, Song Z, Zheng QC. Ligand-based targeted therapy: A novel strategy for hepatocellular carcinoma. Int J Nanomedicine. 2016;11:5645-69. doi: 10.2147/IJN.S115727. [PubMed: 27920520]. [PubMed Central: PMC5127222].

48. Wang Z, Deng X, Ding J, Zhou W, Zheng X, Tang G. Mechanisms of drug release in $\mathrm{pH}$-sensitive micelles for tumour targeted drug delivery system: A review. Int J Pharm. 2018;535(1-2):253-60. doi: 10.1016/j.ijpharm.2017.11.003. [PubMed: 29113804].

49. Salim M, Minamikawa H, Sugimura A, Hashim R. Amphiphilic designer nano-carriers for controlled release: From drug delivery to diagnostics. Med Chem Commun. 2014;5(11):1602-18. doi: 10.1039/c4md00085d.

50. Gill PS, Wernz J, Scadden DT, Cohen P, Mukwaya GM, von Roenn JH, et al. Randomized phase III trial of liposomal daunorubicin versus doxorubicin, bleomycin, and vincristine in AIDS-related Kaposi's sarcoma. J Clin Oncol. 1996;14(8):2353-64. doi: 10.1200/JCO.1996.14.8.2353. [PubMed: 8708728].

51. Adedoyin A, Bernardo JF, Swenson CE, Bolsack LE, Horwith G, DeWit S, et al. Pharmacokinetic profile of ABELCET (amphotericin B lipid complex injection): Combined experience from phase I and phase II studies. Antimicrob Agents Chemother. 1997;41(10):2201-8. doi: 10.1128/AAC.41.10.2201. [PubMed: 9333048]. [PubMed Central: PMC164093].

52. Simon JA; Estrasorb Study Group. Estradiol in micellar nanoparticles: The efficacy and safety of a novel transdermal drugdelivery technology in the management of moderate to severe vasomotor symptoms. Menopause. 2006;13(2):222-31. doi: 10.1097/01.gme.0000174096.56652.4f. [PubMed: 16645536].

53. Hami Z, Amini M, Ghazi-Khansari M, Rezayat SM, Gilani K. 
Doxorubicin-conjugated PLA-PEG-Folate based polymeric micelle for tumor-targeted delivery: synthesis and in vitro evaluation. Daru. 2014;22:30. doi: 10.1186/2008-2231-22-30. [PubMed: 24602477]. [PubMed Central: PMC3996029].

54. Miele E, Spinelli GP, Miele E, Tomao F, Tomao S. Albumin-bound formulation of paclitaxel (Abraxane $₫$ ABI-007) in the treatment of breast cancer. Int J Nanomedicine. 2009;4:99-105. doi:10.2147/ijn.s3061. [PubMed: 19516888]. [PubMed Central: PMC2720743].

55. He W, Xing X, Wang X, Wu D, Wu W, Guo J, et al. NanocarrierMediated Cytosolic Delivery of Biopharmaceuticals. Adv Funct Mater. 2020;30(37):1910566. doi: 10.1002/adfm.201910566. [PubMed: 30582800].

56. Chue P, Chue J. A critical appraisal of paliperidone long-acting injection in the treatment of schizoaffective disorder. Ther Clin Risk Manag. 2016;12:109-16. doi: 10.2147/TCRM.S81581. [PubMed: 26869795]. [PubMed Central: PMC4737499].

57. Schutte JK, Becker S, Burmester S, Starosse A, Lenz D, Kroner L, et al. Comparison of the therapeutic effectiveness of a dantrolene sodium solution and a novel nanocrystalline suspension of dantrolene sodium in malignant hyperthermia normal and susceptible pigs. Eur J Anaesthesiol. 2011;28(4):256-64. [PubMed: 21513076].

58. Graczyk H, Bryan LC, Lewinski N, Suarez G, Coullerez G, Bowen P, et al. Physicochemical characterization of nebulized superparamagnetic iron oxide nanoparticles (SPIONs). J Aerosol Med Pulm Drug Deliv. 2015;28(1):43-51. doi: 10.1089/jamp.2013.1117. [PubMed: 24801912]. [PubMed Central: PMC4367499].
59. Cai X, Liu M, Zhang C, Sun D, Zhai G. pH-responsive copolymers based on pluronic P123-poly(beta-amino ester): Synthesis, characterization and application of copolymer micelles. Colloids Surf B Biointerfaces. 2016;142:114-22. doi: 10.1016/j.colsurfb.2016.02.033. [PubMed: 26945163].

60. Hami Z, Amini M, Ghazi-Khansari M, Rezayat SM, Gilani K. Synthesis and in vitro evaluation of a $\mathrm{pH}$-sensitive PLA-PEG-folate based polymeric micelle for controlled delivery of docetaxel. Colloids SurfB Biointerfaces. 2014;116:309-17. doi: 10.1016/j.colsurfb.2014.01.015. [PubMed: 24503352].

61. Yu H, Jin F, Liu D, Shu G, Wang X, Qi J, et al. ROS-responsive nano-drug delivery system combining mitochondria-targeting ceria nanoparticles with atorvastatin for acute kidney injury. Theranostics. 2020;10(5):2342-57. doi: 10.7150/thno.40395. [PubMed:32104507]. [PubMed Central: PMC7019163].

62. Hettiarachchi SD, Graham RM, Mintz KJ, Zhou Y, Vanni S, Peng $Z$, et al. Triple conjugated carbon dots as a nano-drug delivery model for glioblastoma brain tumors. Nanoscale. 2019;11(13):6192205. doi:10.1039/c8nr08970a. [PubMed: 30874284]. [PubMed Central: PMC6459689].

63. Khurana LK, Singh R, Singh H, Sharma M. Systematic development and optimization of an in-situ gelling system for moxifloxacin ocular nanosuspension using high-pressure homogenization with an improved encapsulation efficiency. Curr Pharm Des. 2018;24(13):143445. doi: 10.2174/1381612824666180403115106. [PubMed: 29611480]. 